\title{
PENGGUNAAN BAHASA UNIK KOMUNITAS WARIA SEBAGAI ALAT KOMUNIKASI DI CIPANAS GARUT
}

\author{
Cecep Hamzah Pansuri, Desi Qoriah \\ Fakultas Ekonomi, Universitas Garut \\ Jln. Raya Samarang No. 52A Garut \\ No.HP: 081323325833, 085222509059 \\ e-mail: cecephamzah@uniga.ac.id,desiq@uniga.ac.id
}

Naskah diterima tanggal 28 Agustus 2020 direvisi tanggal 25 Maret 2021 disetujui tanggal 1 April 2021

\begin{abstract}
Abstrak
Bahasa yang menjadi ciri khas dan unik dalam lingkungan tertentu, termasuk bahasa yang dipakai oleh kaum Waria atau Banci yang memiliki kekhasan tersendiri yang berbeda dengan bahasa pada umumnya. Tujuan dari penelitian ini adalah untuk mengidentifikasi bahasa unik yang digunakan oleh kaum waria di Cipanas Garut dan juga untuk mengetahui bagaimana bahasa tersebut terbentuk. Jenis penelitian ini adalah deskristif kualitatif. Metode penelitian menggunakan wawancara, observasi, menyimak dan mencatat. Hasil penelitian menunjukkan bahwa Waria di cipanas Garut menggunakan bahasa khas waria sebagai komunikasi dengan sesama waria dan orang terdekat, penggunaan bahasa tersebut dipengaruhi juga oleh komunitas waria di luar daerah juga tren bahasa yang dipakai di media-media visual dan audio visual.
\end{abstract}

Kata-kata kunci: Alat komunikasi; bahasa baru; komunitas; ragam bahasa; waria.

\begin{abstract}
Languages which are characteristic and unique. including the languageof transgender which has its own uniqueness which is different from general language. The purpose of this study was to identify the unique language used by transgender in Cipanas Garut and also to find out how the language was formed. This type of research is descriptive qualitative. The research method uses interviews, observation, listening and taking notes. The results showed that transgender in cipanas Garut used the "sissy" language as communication with their fellow and their closest people, the use of this language was also influenced by the transgender community outside the region as well as the trend of language used in visual and audio-visual media.
\end{abstract}

Keywords: Communication tool; new language; community; variety of languages; shemale.

\section{Pendahuluan}

Dalam sebuah pergaulan bahasa tertentu di gunakan sebagai identitas dari satu kalangan. Orang Sunda menggunakan bahasa Sunda, orang Papua menggunakan bahasa papua, itu pemakaian bahasa secara wilayah atau ke sukuan. Tetapi meski satu wilayah ada juga sebuah kalangan memakai bahasa tertentu dengan tujuan agar terlihat trendy atau pun karena tidak ingin dipahami orang lain karena yang dibicarakan hanya boleh diketahui lawan bicaranya dan tidak untuk dimengerti kalangan umum disekitarnya. Keragaman bahasa terbentuk dikarenakan kebutuhan penuturnya atau karena ada penuturnya.

Teori-teori mengenai komunikasi menjadi salah suatu bagian yang paling penting dalam kehidupan manusia karena 
manusia adalah mahluk sosial. Manusia adalah makhluk sosial yang tidak dapat hidup sendiri yang selalu membutuhkan bantuan orang lain. Untuk menjalin hubunganya dengan orang lain adalah dengan komunikasi. Bahasa yang dipakai bisa sangat beragam. Soeparno (2002: 71) mengungkapkan bahwa ragam bahasa atau variasi bahasa adalah keanekaragaman bahasa yang dapat disebabkan oleh faktorfaktor tertentu. Faktor-faktor penyebab keragaman itu terjadi diantaranya seperti faktor kronologis, faktor geografis, faktor sosial, faktor fungsional, faktor gaya/ style, kultural atau budaya, dan faktor individual.

Keefektifitasan komunikasi yang terjadi dan yang dipergunakan akan menjadikan hubungan yang terjalin akan berjalan dengan baik. Ada banyak macam teori-teori komunikasi menurut para ahli yang bisa menjadi rujukan. Dan pemakaian ragam bahasa tertentu dipakai sebagai aturan dalam hal tertentu misalkan bahasa yang dipakai di acara formal akan berbeda dengan bahasa kekerabatan sehari-hari. Ragam bahasa yang dipakai kaum akademis akan berbeda dengan bahasa yang dipakai anak-anak kolong jembatan. Tidak jarang pemakaian bahasa pun dipakai menjadi ukuran prestise sebuah lingkungan. Seperti penelitian Stofleth and Manusov (2019) menyatakan bahwa "popular article definitions emphasized awareness only and referenced the religious basis of mindfulness". Beliau menemukan hasil bahwa bahasa yang dipakai pada artikel jurnalistik dan bahasa-bahas yang dipakai dikalangan agamawan itu memiliki perbedaan. Juga bahasa-bahasa yang dipakai oleh lingkungan tertentu misalkan kalangan medis, kalangan musisi, kalangan akademis itu memiliki ragam tertentu.

Komunikasi bahasa yang digunakan kaum waria di kabupaten Garut khususnya Cipanas juga memiliki ragam yang khas saat seorang waria berkomunikasi dengan sesama waria atau pun berkomunikasi dengan non-waria tetapi sudah dekat dan akrab. Semisal penggunaan kata "makarena" yang artinya "makan" pada kalimat "mawar еkеиии.. mawar makarena iyeeey endolita" kalimat tersebut memiliki arti "mau donk aku mau makan ih kamu.. enak". Hal ini berkaitan dengan teori komunikasi Behavioural nya Watson Teori yang mencakup semua perilaku dan tindakan, termasuk respon (tindakan balasan) terhadap suatu stimulus (rangsangan). Artinya, bahwa ada kaitan antara stimulus dengan respon pada prilaku manusia dalam hali ini timbal balik dua arah dari para waria yang berkomunikasi.

Jumlah waria di kabupaten Garut berdasarkan data terakhir yaitu tahun 2019 yang diambil dari Komisi Penanggulangan AIDS kabupaten Garut yang rutin melakukan penjangkauan pada komunitas waria, adalah 119 orang. Perkembangan jumlah waria dari empat tahun terakhir terhitung dari 2016 sampai tahun 2019 cenderung bertahan diangka sekitar 117 sampai 125 an orang. Tidak ada penambahan yang fluktuatif seperti bisa dilihat pada skema di bawah ini. 


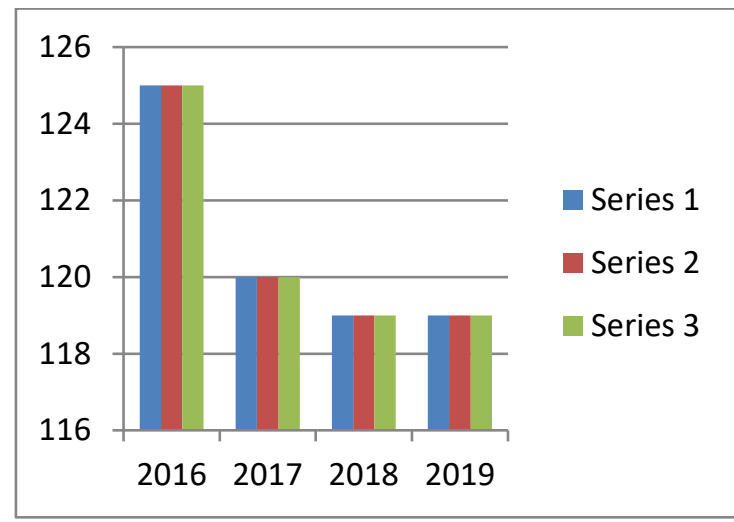

\section{Grafik 1 Penurunan Angka Waria}

Ditemukan penurunan jumlah pada tahun 2018 dan 2019 tetapi tidak berjauh beda. Penurunan angka waria kota Garut diantaranya karena perpindahan tempat ke kota lain, atau juga karena kasus meninggal.

Waria atau Banci merupakan salah satu komunitas yang eksistensinya tidak diragukan di dalam masyarakat meski sering menuai kontriversi dan sebagai salah satu penyumbang dalam pemakaian variasi bahasa terbesar, bahasa-bahasa baru yang mereka ciptakan terbilang unik dan khas, selain itu kosakata- kosakata mereka susah dipahami oleh masyarakat pada umumnya. Tetapi malah dipakai oleh kaum entertaiment dan sering dipakai oleh kalangan artis tertentu. Waria termasuk dalam bagian LGBT (Lesbi, Gay, Bisekusal, Transgender dan Transeksual) yang secara biologis berkelamin laki-laki tetapi berpenampilan serta berperilaku seperti perempuan. Dan demi memeperlihatkan eksistensinya mereka memakai bahasa tertentu. Seiring dengan temuan Bernhold (2020) yang juga menganalisa adanya perbedaan pemakaian bahasa berdasarkan usia sebagai berikut "Findings are discussed in terms of the intergenerational transmission of agerelated communication habits and the theoretical importance of examining moderators that might qualify the links between age-related communication in future research". Jadi sudah menjadi kewajaran apabila kaum waria ini memakai bahasa yang khas dan berbeda

Pemakaian bahasa pada Waria dikatakan Unik karena memiliki ke khasan dan memiliki perbedaan dibanding bahasa pada umumnya. Unik menurut Kamus Besar Bahasa Indonesia artinya tersendiri dalam bentuk atau jenisnya dan atau lain daripada yang lain dan atau tidak ada persamaan. Penggunaan bahasa Waria pun memiliki jenis atau pembentukan sendiri yang berbeda dari yang lain dan memang penuturnya hanya kaum waria atau non waria yang berada dilingkungan tertentu misalnya dunia salon, tata rias dan dunia entertaiment. Keunikan pada bahasa terjadi pada kasus tertentu, seperti penelitian Reidenbach \& Shallit (2019) yang menyatakan "We consider several language-theoretic aspects of various notions of unique decipherability (or unique factorization) in formal languages". Keunikan pemakaian bahasa juga mungkin terjadi bahkan pada bahasa Formal.

Tujuan dari penelitian ini adalah untuk mengidentifikasi bahasa unik yang digunakan oleh kaum waria di Cipanas Garut juga untuk mengetahui bagaimana bahasa tersebut terbentuk. Jenis penelitian ini adalah deskristif kualitatif. Metode penelitian menggunakan wawancara, observasi, menyimak dan mencatat. Teknik analisis data yang digunakan dalam penelitian ini adalah reduksi, penyajian data, dan penarikan kesimpulan / verifikasi.

Dalam masyarakat yang beraneka ragam latar belakang budaya, kebiasaan dan suku maka muncul pula variasi atau 
ragam bahasa yang berbeda-bed. Ragam bahasa ini ada dan muncul karena adanya masyarakat yang heterogen dengan berbagaia macam aktivitas di dalamnya. Kemudian ebih lanjut menurut Suparno (2007), variasi bahasa adalah keanekaragaman bahasa yang disebabkan oleh faktor-faktor tertentu.

Sebuah bahasa dikatakan unik ketika penggunaan bahasa tersebut berbeda dengan bahasa pada umumnya dan memiliki ke khasan tersendiri. Baik dari pembentukan bentuk katanya atau ada variasi-variasi pembentuk imbuhanya. Variasi bahasa juga dapat dibedakan menurut penutur dan pemakaiannya. Variasi bahasa akan selalu berkembang dan bermunculan seiring berkembangnya buadaya masyarakat. Salah satu contohnya adalah bahasa unik yaitu variasi sosial yang bersifat khusus dan bisa jadi mengandung unsur kode dan rahasia. Variasi ini digunakan oleh kalangan tertetntu yang sangat terbatas dan tidak diketahui oleh orang lain di luar kalangan itu (Chaer, 2004).

Penggunaan keragaman bahasa terbagi dapat pula dilihat dari dua pandangan. Pertama, ragam bahasa dilihat dari keberadaanya sebagai akibat eksistensi keragaman sosial penutur bahasa itu dan keragaman fungsi bahasa itu. Dalam arti lain bahasa itu terjadi sebagai akibat keragaman sosial dan keragaman fungsi bahasa. Kedua, ragam bahasa itu sudah ada untuk memenuhi fungsinya sebagai alat interaksi dalam kegiatan masyarakat yang beraneka ragam. Seperti penelitian Franco Salvador (2017) yang juga meneliti mengenai variasi penggunaan bahasa, beliau menyatakan "We design a general approach that combines string kernels and word embeddings, which capture different characteristics of texts". Sudah tak asing lagi bahwa keragaman bahasa itu ada karena ada penuturnya yang beraneka ragam.

Bahasa Waria atau bahasa banci adalah bahasa yang dipergunakan oleh komunitas Waria itu sendiri dan juga di pakai sebagai bahasa gaul atau bahasa trend dikalangan tertentu misalnya di kalangan pelaku bisnis salon dan rias pengantin. Ada yang menggunakan istilah bahasa slang, bahasa prokem waria atau bahasa unik waria. Seperti Chaer (2010: 67) mendeskripsikan bahwa bahasa slang adalah variasi sosial yang bersifat khusus dan rahasia. Dalam arti ragam bahasa ini digunakan oleh kalangan tertentu yang terbatas dan tidak banyak diketahui oleh kalangan diluar kelompok itu. Oleh karena itu, kosakata yang digunakan dalam slang ini seringkali berubah-ubah.

Bahasa Waria dikatakan unik karena memiliki ciri khas yang membuat telinga terasa penasaran mendengarnya, bahkan tidak jarang bahasa waria ini ditiru banyak kalangan karena keunikanya. Misalkan ta "cap cuzz" yang sering dikatakan anak muda untuk mengganti kata "ayo". Kosakata tersebut diciptakan tidak semata-mata untuk merusak tata bahasa baku atau formal, melainkan untuk menjadi identitas diri yang membedakan komunitas waria/Banci dengan masyarakat umum. Bahkan dipakai untuk sebuah kode komunikasi agar isi komunikasi tidak dipahami oleh masyarakat umum disekitarnya. Terbentuknya bahasa-bahasa unik ini mungkin muncul untuk kepentingan tertentu, senada dengan penelitian Cowley (2019) yang menyatakan "Turning to language, I sketch how the model applies 
Jurnal Komunikasi Universitas Garut: Hasil Pemikiran dan Penelitian

Vol. 7, No. 1, April 2021

Halaman 617-626

to writing and reading. Like Morse operators, writers resemiotize a code-like domain of alphabets, spelling-systems". Bahkan bahasa pun memiliki perbedaan meski untuk dibedakan mana bahasa tulisan mana bahasa verbal.

Bahasa terbentuk sebagai kebutuhan manusia untuk menyampaikan ide, pemikiran, perasaan, keinginan dan lain sebagainya kepada lawan bicara atau kepada orang sekitar. Seperti diungkapkan oleh sebuah teori yaitu teori "informatif" yang merupakan salah satu teori klasik, dimana teori ini menitikberatkan pada komunikasi sebagai suatu transmisi pesan dan bagaimana transmitter menggunakan media dalam berkomunikasi. Dalam teori informatif, jika sinyal media yang dipakai baik, maka komunikasi berjalan efektif. Namun sebaliknya, jika sinyal media yang digunakan tidak baik, maka komunikasi tidak berjalan lancar (Sannon \& Weaver, 1994).

Sebuah bahasa hadir dan eksis karena ada pemakainya. Pemakaian bahsa tergantung kepada siapa pemakainya. Bahasa yang dipakai dikalangan tertentu bisa saja berbeda dengan bahasa yang dipakai di lingkungan yang lain. Seperti halnya pembentukan bahasa waria/banci terbentuk karena sengaja di ciptakan untuk kepentingan para pemakainya yang memiliki tujuan tertentu. Fungsi sebuah bahasa hadir dan di buat karena pemakainya mencari cara untuk kemudahan menyampaikan sesuatu, selaras dengan penelitian Prinsloo, C. (2018) yang menyatakan "While the language learning function appears to be a natural extension of reading short stories, they may also perform other functions in English language teaching". Sebuah fungsi bahasa muncul karena tujuan tertentu.

Terbentuknya Bahasa Waria/ Banci di sebuah daerah juga kemungkinan karena kebutuan tertentu dari para pemakainya untuk tujuan tertentu misalkan untuk kebutuhan prestise, kebutuhan sebuah kode bahasa, atau bisa pula karena terpengaruh oleh lingkungan kaum tertentu di daerah lain. Bahasa Waria juga bisa muncul dan digunakan untuk memfasilitasi hal-hal yang selama ini tidak nyaman bagi waria sebagai kaum minoritas dan terpinggirkan di kalangan umum. Demuro \& Gurney (2021) dalam penelitianya mengenai kemunculan sebuah bahasa menyatakan "Across many domains, language is performed as object in ways which are so naturalised that they are unquestioned". Terbentuknya bahasa waria di sebuah lokasi karena para pemakainya merasa menemukan cara untuk saling menyampaikan tujuan dengan nyaman dan memfasilitasi keinginanya sehingga bahasa tersebut tumbuh dan dipergunakan.

Road map penelitian ini dapat dilihat seperti dibawah ini:

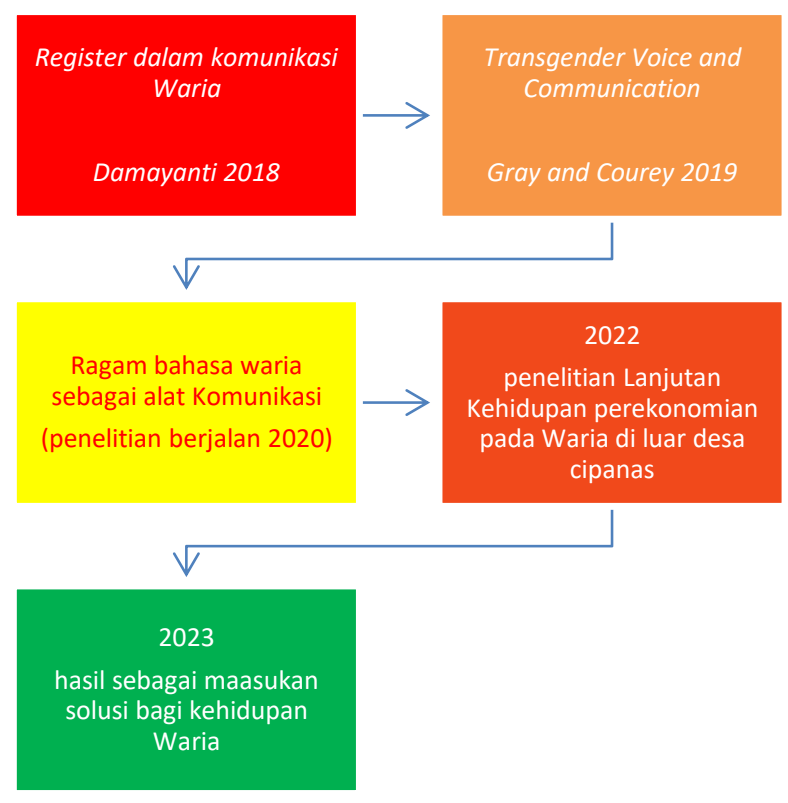




\section{Metode Penelitian}

Metode penelitian menggunakan metode wawancara, observasi, menyimak dan mencatat. Teknik analisis data yang digunakan dalam penelitian ini adalah reduksi, penyajian data, dan penarikan kesimpulan / verifikasi. Metode yang digunakan pada penelitian ini adalah metode deskripsi, dimana metode ini merupakan tata cara mendeskripsikan atau menggambarkan data-data penelitian yang diperoleh melalui wawancara, dan pengamatan langsung dilapangan terutapa pada hots spot area dimana para waria atau banci sering berkumpul. Teknik pengumpulan data dilakukan melalui wawancara, pengamatan lapangan, menyimak dan mencatat.

Sumber data utama dalam penelitian ini adalah dengan sample para waria yang berlokasi di cipanas Garut yang sering berkumpul di Eka Salon dan tata rias pengantin yang berjumlah tujuh orang. Peneliti melakukan wawancara mengenai bahasa-bahasa yang sering digunakan dalam berkomunikasi dengan sesama waria juga mencari data mengapa bahasa tersebut bisa ada dan digunakan diantara mereka. Data sekunder atau data pendukung juga diperoleh melalui para pemakai lain selain waria/ banci yang juga menggunakan bahasa waria pada saat tertentu, selain itu data sekunder juga diperoleh melalui kajian pustaka dari referensi penelitian-penelitian yang terdahulu.
Jenis penelitian yang digunakan yaitu penelitian kualitatif deskriptif. Sugiyono (2015: 15) menjelaskan bahwa penelitian kualitatif adalah penelitian yang berlandaskan pada filsafat postpositivisme (memandang realitas/gejala/fenomena), digunakan untuk meneliti kondisi obyek yang alamiah dimana peneliti adalah sebagai instrument kunci. Metode yang digunakan pada penelitian ini adalah metode deskripsi, dimana metode ini merupakan tata cara menggambarkan data-data penelitian. Pendekatan penelitian yang digunakan peneliti adalah pendekatan sosiolinguistik.

\section{Hasil Penelitian dan Pembahasan}

Hasil dan pembahasan dalam penelitian ini disajikan sesuai dengan rumusan yang sudah dipaparkan terlebih dahulu yaitu mengidentifikasi ragam bahasa unik yang dipergunakan waria/banci Cipanas Garut serta mengetahui faktor-faktor yang mempengaruhi mengapa bahasa waria tersebut bisa hadir dan dipergunakan.

Hasil temuan mengenai ragam bahasa unik yang dipergunakan komunitas waria/banci yang ada di Cipanas Garut lebih dari seratus kata tepatnya sebanyak seratus tiga puluh (130) kata. Kata - kata unik tersebut tidak dugunakan setiap saat tetapi hanya jika dibutuhkan pada saat tertentu misalkan pada situasi dimana pembicaraan mengandung hal yang tidakmau diketahui orang di sekitar. Berikut list ragam bahasa unik yang di pergunakan waria di Cipanas Garut :

Tabel 1

Ragam Bahasa Waria Cipanas Garut

\begin{tabular}{lllcll}
\hline No & Bahasa Waria & $\begin{array}{c}\text { Arti dalam } \\
\text { bahasa umum }\end{array}$ & No & Bahasa Waria & $\begin{array}{c}\text { Arti dalam bahasa } \\
\text { umum }\end{array}$ \\
\hline 1 & Ekeu & Aku & 66 & Jijaay & Jijik \\
2 & Aminah & Aman & 67 & Jula-jali & Jual \\
\hline
\end{tabular}


Jurnal Komunikasi Universitas Garut: Hasil Pemikiran dan Penelitian

Vol. 7, No. 1, April 2021

Halaman 617-626

\begin{tabular}{|c|c|c|c|c|c|}
\hline 3 & Apose & Apa & 68 & Jumpalitan & Jumpa \\
\hline 4 & Australia & Haus & 69 & Kalimantan & Kalian \\
\hline 5 & Azizah & Ajak-ajak & 70 & Kamasutra & Kemaren \\
\hline 6 & Bancakan & Banci & 71 & Kampus biru & Kampungan \\
\hline 7 & Bagaskara & Bagus & 72 & Kasiman & Kasihan \\
\hline 8 & Bajay & Baju & 73 & Kencana & Kencing \\
\hline 9 & Banyengnyong & Banyak & 74 & Kosidah & Kos an \\
\hline 10 & Barbara & Baru & 75 & Kursi & Kurus \\
\hline 11 & Bewes & Bawa & 76 & Lambreta & Lama \\
\hline 12 & Belalang & Beli & 77 & Lekong & Lelaki \\
\hline 13 & Belanda & Belum & 78 & Lapangan & Lapar \\
\hline 14 & Belenjong & Belanja & 79 & Lupita & Lupa \\
\hline 15 & $\begin{array}{l}\text { Beranak dalam } \\
\text { kubur }\end{array}$ & Berak & 80 & Macica & Macet \\
\hline 16 & Brepong & Berapa & 81 & Maharani & Mahal \\
\hline 17 & Besolfon & Besok & 82 & Mekong & Makan \\
\hline 18 & Birahi & Biru & 83 & Malasya & Malas \\
\hline 19 & Bisikan & Bisa & 84 & Maluku & Malu \\
\hline 20 & Bulgari & Bule & 85 & Matilda & Mati \\
\hline 21 & Butceri & Bule cat sendiri & 86 & Mawar & Mau \\
\hline 22 & Cacamarica & Cari & 87 & Minahasa & Minum \\
\hline 23 & Cap cai & Cepat & 88 & Miskrina & Miskin \\
\hline 24 & Cap cuss & Pergi & 89 & Mursida & Murah \\
\hline 25 & Capung & Cape & 90 & Nantra & Nanti \\
\hline 26 & Cintrong & Cinta & 91 & Ngobras & Ngobrol \\
\hline 27 & Cumi-cumi & Cium & 92 & Nurjana & Norak \\
\hline 28 & Cucok & Keren/ganteng & 93 & Nyengnyong & Nyanyi \\
\hline 29 & Dadar & Dari & 94 & Oberta & Obat \\
\hline 30 & Dendong & Dangdan & 95 & Organda & Orang \\
\hline 31 & Dataran & Datang & 96 & Pancaroba & Pacar \\
\hline 32 & Deseu & Dia & 97 & Pastiles & Pasti \\
\hline 33 & Ding dong & Dingin & 98 & Pecongan & Pacaran \\
\hline 34 & Dukun & Duduk & 99 & Pelita & Pelit \\
\hline 35 & Duta & Duit & 100 & Pewong & Perempuan \\
\hline 36 & Ekeu & $\mathrm{Aku}$ & 101 & Pepsi & Pipis \\
\hline 37 & Egp & Emang gw pikirin & 102 & Pertiwi & Perut \\
\hline 38 & Embeer & Emang & 103 & Polda & Pulang \\
\hline 39 & Endolita / endees & Enak & 104 & Puyunghai & Pusing \\
\hline 40 & Falsafah & Palsu & 105 & Ramayana & Ramai \\
\hline 41 & Gajah & Gaji & 106 & Rebong & Raba \\
\hline 42 & Galaxy & Galak & 107 & Rexona & Rokok \\
\hline 43 & Gedes & Gede & 108 & Rumputan & Rumah \\
\hline 44 & Gilingan & Gila & 109 & Sakinah & Sakit \\
\hline 45 & Gindang & Gini & 110 & Samarinda & Sama \\
\hline 46 & Gretong & Gratis & 111 & Sakrina & Sekarang \\
\hline 47 & Gusdur & Gusar/gelisah & 112 & Sekong & Sakit \\
\hline 48 & Habiba & Habis & 113 & Sendora & Sendiri \\
\hline 49 & Hamidah & Hamil & 114 & Seriosa & Serius \\
\hline 50 & Hasanudin & Hasil & 115 & Serundeng & Seru \\
\hline 51 & Herman & Heran & 116 & Sindang & Sini \\
\hline 52 & Homreng & Homo / gay & 117 & Sirsak & Sirik \\
\hline 53 & Hepong & Happy/ hura-hura & 118 & Sparta & Sepatu \\
\hline 54 & Hujriah & Hujan & 119 & Supardin & Sopir \\
\hline 55 & Incess & Putri & 120 & Sutra & Sudah \\
\hline 56 & Istana & Istri & 121 & Susana & Susah \\
\hline 57 & Indang & Ini & 122 & Takara & Takut \\
\hline 58 & Jaguar & Jagoan & 123 & Tanjakan & Tanya \\
\hline 59 & Jelong-jelong & Jalan-jalan & 124 & Telepati & Telepon \\
\hline 60 & Jajamiharja & Jajan mie & 125 & Tinta & Tidak \\
\hline
\end{tabular}


Jurnal Komunikasi Universitas Garut: Hasil Pemikiran dan Penelitian

Vol. 7, No. 1, April 2021

Halaman 617-626

\begin{tabular}{|c|c|c|c|c|c|}
\hline 61 & Jangkar & Jangan & 126 & TTDJ & Hati-hati di jalan \\
\hline 62 & Jauhari & Jauh & 127 & Tol jagorawi & Tolol \\
\hline 63 & Jayus & Bcanda garing & 128 & Turnamen & Turun \\
\hline 64 & Jelita & Jelek & 129 & Udong & Sudah \\
\hline 65 & Jendes & Janda & 130 & Usmawi & Suami \\
\hline
\end{tabular}

Terdapat beberapa kata dari ragam

bahasa Waria yang diadopsi oleh masyarakat non waria yang malah digunakan sebagai kata gaul. Misalkan kata ttdj yang artinya "hati-hati di jalan" seperti penggunaan dalam kalimat berikut :

Pembicara A: "Guys, aku pulang duluan yaaa"

Pembicara B: "okeee, TTDJ" Atau kata "endolita" sebagai kata "enak" seperti dalam kalimat : "eh cobain makarena di pesta baso aci, rasanya endolita". Dan ada banyak lagi bahasa waria yang dipakai oleh masyarakat selain waria terutama pada kalangan remaja dan lingkungan bergaul. Pemakai bahasa waria pada non waria menggunakan bahasa waria ini sebagai sarana aktualisasi diri bahwa mereka adalah golongan yang tidak kurang bergaul. Setidaknya seperti itu hasil wawancara peneliti dengan beberapa sample non waria yang sering menggunakan bahasa waria.

Komunikasi komunitas waria juga tidak setiap saat menggunakan bahasa tersebut. Dalam interaksi sehari-hari baik dengan sesama waria ataupun dengan masyarakat umum, waria sering juga menggunakan bahasa sehari-hari pada umumnya. Pemakaian bahasa unik itu digunakan ketika situasi tertentu saja, salah satunya ketika ada beberapa orang di dekatnya memang mengerti bahasa tersebut meskipun seseorang tersebut bukan waria. Atau bahasa ini juga digunakan pada saat posisi waria terancam oleh lingkungan sehingga mendorong para

waria untuk berkomunikasi yang tidak dipahami orang-orang disekitarnya.

Bahasa waria digunakan dengan sesama waria dihadapan hal layak juga bisa karena ingin menyampaikan sesuatu yang seharusnya disembunyikan, misalkan seperti dalam kalimat: "iyey, deseu gilingan karena sirsak mukena jelita” yang artinya waria tersebut langi ngomongin seseorang di dekatnya tapi tidak mau orang tersebut mengetahuinya. Arti kalimat diatas adalah " eh kamu, si dia gila ya karena sirik mukanya jelek"

Pembahasan selanjutnya adalah mengenai faktor yang mempengaruhi mengapa pemakaian bahasa waria sebagai alat komunikasi ini ada dan dipakai di Cipanas Tarogong Garut ini. Seperti telah diungkapkan di atas sebuah bahasa ada dan hadir karena ada pemakainya. Adapun hal yang mempengaruhi pemakaian bahasa waria ini salah satunya adalah karena adanya interaksi dengan komunitas waria dari daerah lain. Dan juga karena adanya kebutuhan untuk menggunakan bahasa ini, sehingga ada pembelajaran tidak langsung misalkan melalui media audio ataupun visual seperti dari radio atau televisi.

Faktor lain yang mempengaruhi tumbuhnya bahasa waria ini adalah karena ada waktu dan tempat. Artinya bahasa ini tersebar dan tumbuh karena ada waktu untuk menuturnya juga ada wadah yang memfasilitasi para penutur ini untuk berkomunikasi nyata dengan bahasa ini. Di Kabupaten Garut Sendiri para Waria membentuk komunitas sendiri untuk mewadahi eksistensinya. Komunitas 
tersebut bernama "Serikandi Papandayan". Komunitas ini dibentuk agar mampu menampung dan memotivasi waria untuk tetap bertahan hidup ditengah penolakan dan tetap bisa berkarya nyata.

Hal lainya adalah karena adanya peserta tutur. Peserta tutur artinya pemakai bahasa tersebut yang ada pengaruh dari pemakai bahasa waria dari luar kota Garut tetapi di kombinasikan dengan aksen dan bahasa daerah tersebut. Itu makanya meskipun sama-sama bahasa waria tetapi memiliki perbedaan antara waria dari daerah yang satu dengan daerah yang lain. Misalkan bahasa waria untuk kata “ makan", ada yang memakainya dengan kata "mekong" ada pula daerah lain dengan kata "makarena". Atau juga penggunaan bahasa "enak" ada yang memakai kata "endes" ada pula yang menggunakan "endolita". Begitulah terjadinya pembentukan dan penggunaan sebuah bahasa di kalangan tertentu.

\section{Kesimpulan}

Berdasarkan pembahasan diatas maka dapat disimpulkan bahwa :

Ragam bahasa yang dipakai di Cipanas Garut sebagai sarana untuk berkomunikasi deangan sesama waria berjumlah seratus tiga puluh (130) kata dengan bentuk akhiran yang beragam seperti berakhiran ong, -es, -lita dan sebagainya. Pengguanaan ragam bahasa tersebut memang tidak di gunakan setiap saat, tetapi dipergunakan hanya pada situasi tertentu yang menuntut untuk dipergunakan dengan tujuan tertentu misalkan saat menyampaikan rahasia.

Faktor yang mempengaruhi penggunaan bahasa waria di Cipanas Tarogong Garut adalah sebagai berikut:
1. Adanya interaksi dengan komunitas waria dari daerah lain. Dan juga karena adanya kebutuhan untuk menggunakan bahasa ini, sehingga ada pembelajaran tidak langsung misalkan melalui media audio ataupun visual seperti dari radio atau televisi.

2. Waktu dan tempat. Artinya bahasa ini tersebar dan tumbuh karena ada waktu untuk menuturnya juga ada wadah yang memfasilitasi para penutur ini untuk berkomunikasi nyata dengan bahasa ini. Komunitas Waria di Garut bernama "Serikandi Papandayan"

3. Adanya peserta tutur. Peserta tutur artinya pemakai bahasa tersebut yang ada pengaruh dari pemakai bahasa waria dari luar kota Garut tetapi di kombinasikan dengan aksen dan bahasa daerah tersebut.

Berdasarkan kesimpulan yang dapat disajikan dalam penelitian ini, maka penulis pun menemukan beberapa saran diantaranya :

1. Ragam bahasa waria hendaknya memiliki tempat yang baik dan dapat dihargai oleh masyarakat umum, karena diakui atau tidak, fakta dilapangan bahasa waria ini memiliki prestise tersendiri ketika dipakai sebagai bahasa gaul.

2. Masyarakat umum dapat lebih menerima lagi keberadaan waria dengan memperlakukan waria sebagaimana manusia yang mendapat hak yang sama untuk hidup, bekerja, menikmati fasilitas umum dan hal lain sebagainya.

3. Penelitian ini dapat dijadikan acuan pada penelitian lain mengenai bahasa yang dipergunakan oleh waria. 
Jurnal Komunikasi Universitas Garut: Hasil Pemikiran dan Penelitian

Vol. 7, No. 1, April 2021

Halaman 617-626

\section{Daftar Pustaka}

Abdul Chaer. (2004). Tata Bahasa Praktis Bahasa Indonesia. Jakarta: Rineka Cipta.

Abdul. (2010). Kesantunan Berbahasa. Jakarta: Rineka Cipta.

Bernhold, Q. S. (2020). Patterns of agerelated communication in families: A three-generation study. Language \& Communication, 72, 79-92. doi:10.1016/j.langcom.2020.02.00 4

Bell, P. C., Reidenbach, D., \& Shallit, J. O. (2019). Unique decipherability in formal languages. Theoretical Computer Science. doi:10.1016/j.tcs.2019.11.022

Cowley, S. J. (2019). Wide coding: Tetris, Morse and, perhaps, language. Biosystems, 104025. doi:10.1016/j.biosystems.2019.104 025 Chaer.

Data Pisik Penjangkauan LGBT (Lesbian, Gay, Bisex and Transgender). (2019). Komisi Penanggulangan AIDS kabupaten Garut Jawa Barat.

Dardjowidijojo, Soenjono. 2010. Psikolinguistik: Pengantar Pemahamanan Bahasa.

Demuro, E., \& Gurney, L. (2021). Languages/languaging as worldmaking: the ontological bases of language. Language Sciences, 83, 101307.

doi:10.1016/j.langsci.2020.101307

Fatimah jajasudarma. 2010. Metode Linguistik:

Franco-Salvador, M., Kondrak, G., \& Rosso, P. (2017). Bridging the Native Language and Language Variety Identification Tasks. Procedia Computer Science, 112, 1554-1561. doi:10.1016/j.procs.2017.08.068

Paul Suparno. (2007). Filsafat Konstruktivisme dalam Pendidikan. Yogyakarta: Kanisius.
Purwanto. 2006. Psikologi Pendidikan. Bandung: Remaja Rosdakarya.

Prinsloo, C. (2018). Students' intrinsic perspectives on the diverse functions of short stories beyond language learning. System, 74, 8797.

doi:10.1016/j.system.2018.02.019

Soeparno. 2002. Dasar-Dasar Linguistik Umum. Yogyakarta: Tiara Wacana Yogya.

Stofleth, D., \& Manusov, V. (2019). Talking about mindfulness: An ethnography of communication analysis of two speech communities. Language \& Communication, 67, 45-54. doi:10.1016/j.langcom.2018.12.00 3 